\title{
可见光引发的氧自由基的新型产生方式及反应
}

\author{
张晶陈以昀* \\ (中国科学院上海有机化学研究所生命有机化学国家重点实验室 上海 200032)
}

\begin{abstract}
摘要 羧酸自由基及烷氧自由基等氧自由基是有机合成中的重要中间体，近些年通过可见光引发的氧化还原反应产生 此类自由基的研究取得重要进展. 本综述文章将聚焦于羧酸衍生物及羧酸作为羧酸自由基前体, 醇衍生物及醇作为烷 氧自由基前体, 在光催化氧化还原条件下发生单电子转移产生氧自由基的新型方式, 并将简单介绍其后续反应. 关键词 可见光; 自由基反应; 羧酸自由基; 烷氧自由基
\end{abstract}

\section{Visible-Light-Induced Carboxyl and Alkoxyl Radical Generations and Reactions}

\author{
Zhang, Jing Chen, Yiyun* \\ (State Key Laboratory of Bioorganic and Natural Products Chemistry, Shanghai Institute of Organic Chemistry, \\ Chinese Academy of Sciences, Shanghai 200032)
}

\begin{abstract}
The carboxyl and alkoxyl radicals generated from visible light photoredox reactions are important reaction intermediates in organic synthesis, which have witnessed conceivable progress recently. In this review, we focus on visible-light-induced photoredox methods to generate carboxyl radicals from carboxylate derivatives and carboxylates, as well as alkoxyl radicals from alcohol derivatives and alcohols, and briefly discuss their synthetic applications.
\end{abstract}

Keywords visible light; radical reaction; carboxyl radical; alkoxyl radical

\section{1 引言}

羧酸和醇是便宜、易得、种类丰富的含氧化合物原 料. 烷基羧酸自由基及羰基羧酸自由基可以发生脱羧反 应产生烷基及酰基自由基 ${ }^{[1 \sim 4]}$, 烷氧自由基可以发生 1,5 -氢迁移、 $\beta$-裂解、环化等反应产生相应的烷基自由 基 $^{[5 \sim 7]}$. 这些烷基及酰基自由基可以进一步被自由基或 自由基受体捕获构建具有合成价值的碳-碳键及碳-杂 键. 传统产生羧酸自由基和烷氧自由基的方法包括紫外 光照射、 $\mathrm{AIBN} / \mathrm{Bu}_{3} \mathrm{SnH} /$ 加热、强氧化剂等, 然而这些较 为剧烈的反应条件限制了其化学选择性及官能团兼容 性. 近些年可见光催化氧化还原反应领域得到迅速发 展, 产生了多种氧自由基新型形成方法. 这些新方法弥 补了氧自由基传统产生方法的局限性, 实现了羧酸自由 基与烷氧自由基在温和条件下的生成(Scheme 1).

可见光催化反应具有使用简单、易操作等特点, 是 有机合成的一类独特方法. 由于可见光催化反应具有温 和的反应条件及优秀的化学选择性, 此类反应在现代有 机化学及化学生物学研究中具有良好的应用前景 ${ }^{[8 \sim 12]}$. 根据催化剂的催化历程不同, 可以将可见光催化反应分 为氧化淬灭、还原淬灭、能量转移过程. 光催化剂在可
见光照射下变为激发态的光催化剂*, 激发态的光催化 剂*既可以得到一个电子成为还原态的光催化剂实现还 原淬灭循环过程，也可以失去一个电子成为氧化态的光 催化剂实现氧化淬灭循环过程，同时也可以与底物发生 能量转移过程.

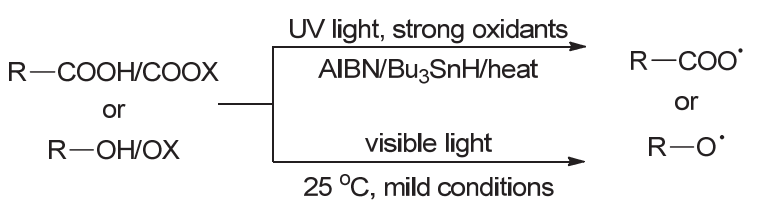

图式 1 通过传统方法及光催化氧化还原方法产生氧自由基 Scheme 1 The oxy radical generation by conventional methods and visible light photoredox methods

在光催化氧化还原条件下, 激发态的光催化剂与还 原态的光催化剂可以作为还原剂还原羧酸衍生物与醇 衍生物, 激发态的光催化剂与氧化态的光催化剂可以作 为氧化剂氧化羒酸与醇或者当场活化的羧酸与醇. 本综 述将聚焦于氧自由基前体在可见光催化氧化还原条件 下与不同氧化还原剂的典型反应方式, 并对后续相关反 应做简要介绍。

\footnotetext{
*E-mail: yiyunchen@sioc.ac.cn

Received August 15, 2016; published December 2, 2016.
}

Project supported by the National Basic Research Program of China (No. 2014CB910304), National Natural Science Foundation of China (Nos. 21272260, 21472230) and the Strategic Priority Research Program of the Chinese Academy of Sciences (No. XDB20020200).

项目受国家重大科学研究计划项目(No. 2014CB910304)、国家自然科学基金(Nos. 21272260, 21472230)和中国科学院战略性先导科技专项(B 类)(No. XDB20020200)资助. 


\section{2 可见光引发羧酸自由基的产生及反应}

\section{1 羧酸衍生物作为自由基前体}

在光催化氧化还原条件下, 还原态的光催化剂及激 发态的光催化剂均可进行单电子还原羧酸衍生物产生 羧酸自由基. 1991 年, Okada/Oda 课题组 ${ }^{[13]}$ 报道了烷基 羧酸衍生物 $N$-酰氧邻苯二甲酰亚胺 $\mathbf{1}$ 在 BNAH 作为还 原剂的可见光催化还原条件下, 被还原态的光催化剂 $\mathrm{Ru}(\mathrm{I})$ 单电子还原产生羧酸自由基. 该烷基羧酸自由基 可以脱羧产生烷基自由基, 之后发生共轭加成等成键反 应(Scheme 2). 2012 年, Overman 课题组 ${ }^{[14]}$ 报道了 $N$-酰氧 邻苯二甲酰亚胺在汉斯酯和二异丙基乙胺的可见光催 化还原条件下, 被还原态的光催化剂 $\mathrm{Ru}(\mathrm{I})$ 单电子还原 产生羧酸自由基, 之后脱羧产生三级烷基自由基并发生 共轭加成反应实现(一)-Aplyviolene 的全合成.

2015 年, 陈以昀课题组 ${ }^{[15]}$ 报道了 $N$-酰氧邻苯二甲 酰亚胺在抗坏血酸的可见光催化还原条件下被还原态 的光催化剂 $\mathrm{Ru}(\mathrm{I})$ 单电子还原产生羧酸自由基. 该类可 见光催化还原条件不仅可以在有机相中顺利进行, 在中 性水相体系中也可进行，并且与氨基酸、核苷、寡糖、 核酸、蛋白及细胞裂解液等生物分子体系兼容, 同时蛋 白酶的活性在该反应体系中不受影响. 脱羧烯丙基化反 应可在中性水溶液中以 $100 \mu \mathrm{mol} / \mathrm{L}$ 的低底物浓度快速 进行 $(1 \mathrm{~min})$, 从而为该类可见光引发反应在生物体系中 的应用打下良好基础 ${ }^{[16]}$.

2013 年, 朱成建课题组报道了醋酸碘苯 9 作为羧酸 衍生物被激发态的 $\operatorname{Ir}(\mathrm{III})$ *还原生成乙酸自由基, 之后发 生脱羧及 C-H 官能化串联反应, 最后被 $\operatorname{Ir}(\mathrm{IV})$ 氧化生成 目标产物 11. 该反应也适用于其它烷基羧酸碘苯的衍
生物并可应用于异腈的加成反应(Scheme 3) ${ }^{[17,18]} .2013$ 年, Reiser 课题组 ${ }^{[19]}$ 发现 $N$-酰氧邻苯二甲酰亚胺可以被 激发态的光催化剂 $\operatorname{Ir}(\mathrm{III}) *$ *还原生成羧酸自由基, 进而进 攻分子内的呋喃并被 $\operatorname{Ir}(\mathrm{IV})$ 氧化生成螺环化合物.

\section{2 羒酸作为自由基前体}

光催化氧化条件下, 羧酸或者当场活化的羒酸可以 被氧化态光催化剂、反应体系中产生的其它氧化物种、 及激发态的光催化剂氧化. 2014 年, MacMillan 课题 组 ${ }^{[20,21]}$ 报道了 $\alpha$-氨基酸及 $\alpha$-羟基酸 12 在芳基腈 13 作为 氧化剂的可见光催化氧化条件下，被氧化态的光催化剂 $\operatorname{Ir}(\mathrm{IV})$ 单电子氧化产生羧酸自由基，之后脱羧产生烷基 自由基 15 进而与芳基腈自由基负离子反应生成芳基化 产物(Scheme 4).

2014 年, 雷爱文课题组报道了酮酸 19 在氧气存在 的光催化氧化体系下, 被超氧阴离子自由基 20 单电子 氧化产生酩酸自由基 21 (Scheme 5) ${ }^{[22]}$. 酮酸自由基 21 脱羧产生酰基自由基 22, 并被脂肪胺或芳香胺 23 进攻 产生酰胺产物 24. 该反应中，激发态的 $\mathrm{Ru}(\mathrm{II})^{*}$ 被胺还原 生成 $\mathrm{Ru}(\mathrm{I})$, 再作为还原剂将氧气还原为超氧阴离子自 由基 20.

2015 年, MacMillan 课题组 ${ }^{[23]}$ 报道了酮酸 28 在光催 化/过渡金属催化的双催化体系下，被激发态的光催化 剂 $\operatorname{Ir}(\mathrm{III})$ *单电子氧化产生酮酸自由基(Scheme 6). 酮酸 自由基脱羧产生酰基自由基 $\mathbf{2 9}$, 并加成至 $\mathrm{Ni}(0)$ 与芳基 卤化物的 $\mathrm{Ni}(\mathrm{II})$ 复合物 $\mathbf{3 0}$ 从而产生 $\mathrm{Ni}$ (III)复合物中间体 31, 最终发生还原消除反应得到酰基的芳基化产物 32 . 2015 年, 傅尧课题组 ${ }^{[24]}$ 报道了酮酸被激发态的光催化 剂 $\operatorname{Ir}(\mathrm{III}) *$ 单电子氧化产生酮酸自由基并脱羧产生酰基 自由基，进而发生对双键的自由基加成反应.

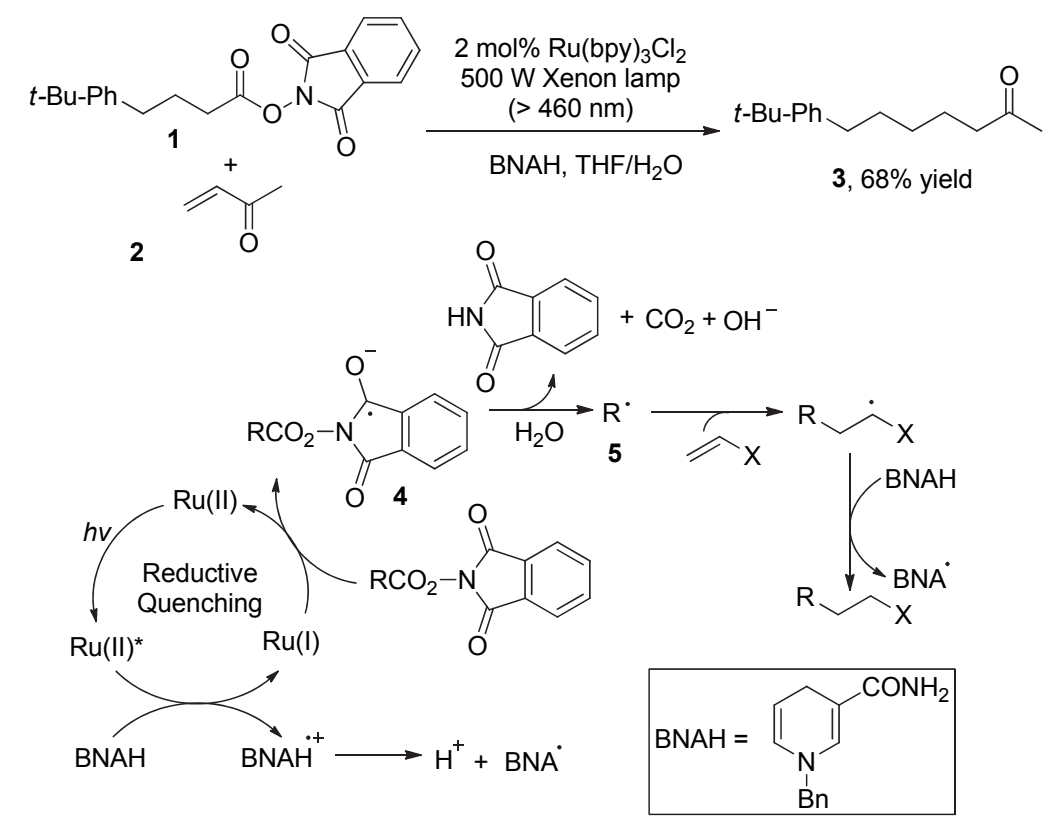

图式 2 还原态光催化剂还原 $N$-酰氧邻苯二甲酰亚胺产生羧酸自由基

Scheme 2 The carboxyl radical generation from $N$-acyloxyphthalimides reduction with reduced photocatalyst 


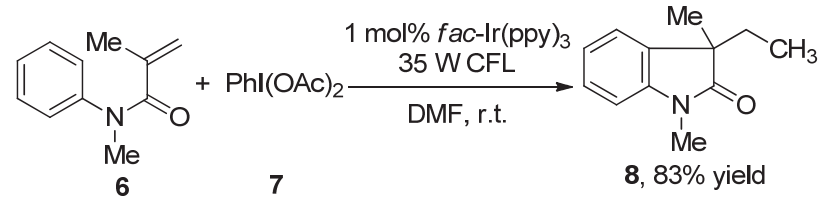

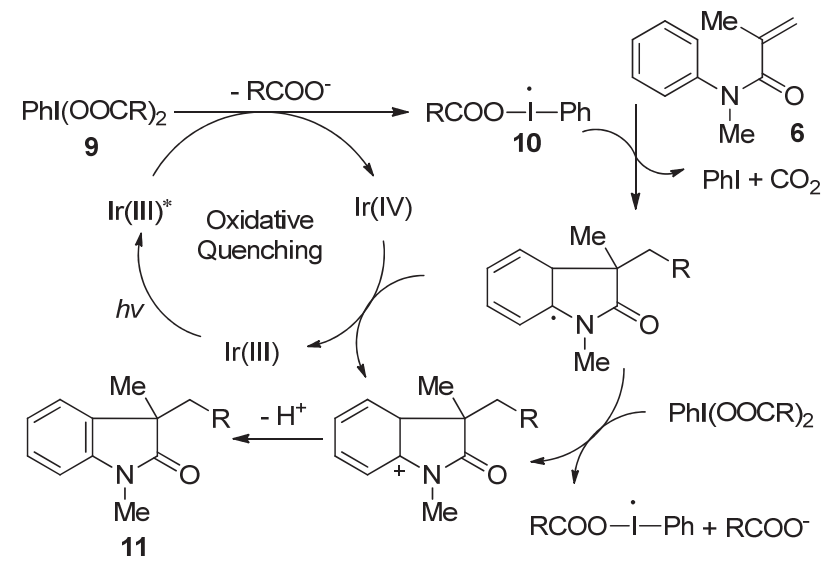

图式 3 激发态光催化剂还原醋酸碘苯产生羧酸自由基

Scheme 3 The carboxyl radical generation from phenyliodine(III) diacetate reduction with excited photocatalyst
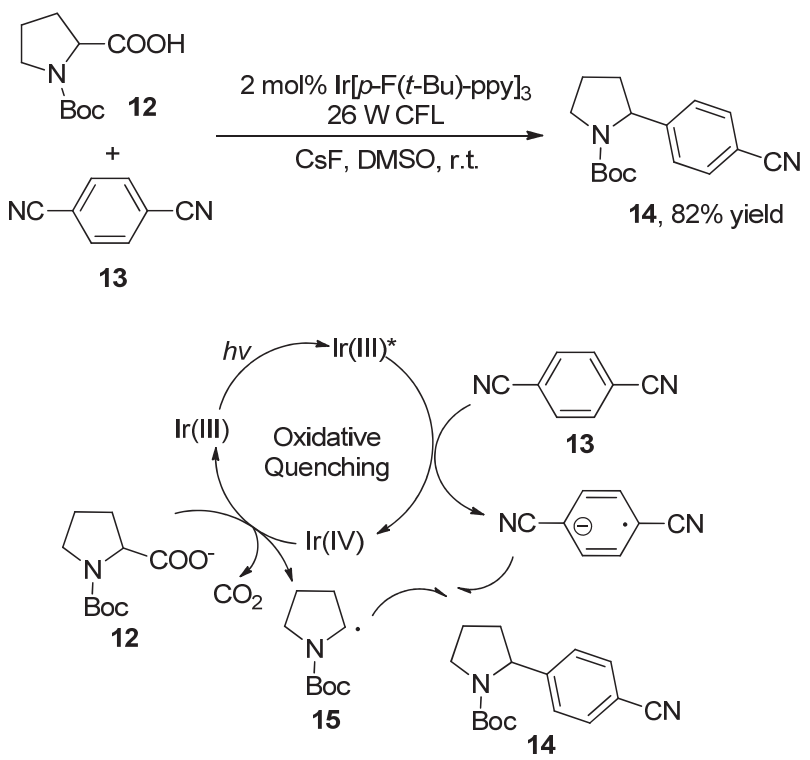

图式 4 氧化态光催化剂直接氧化羒酸产生羧酸自由基

Scheme 4 The carboxyl radical generation from direct carboxylate oxidation with oxidized photocatalyst

2015 年, 肖文精课题组 ${ }^{[25]}$ 与 Waser 课题组 ${ }^{[26]}$ 报道了 烷基羧酸在光催化体系下, 被激发态的光催化剂 $\operatorname{Ir}(\mathrm{III})^{*}$ 单电子氧化产生烷基羧酸自由基. 烷基羧酸自由基脱羧 产生烷基自由基，并加成至高价碘炔基化合物产生烷基 炔基化产物. 该烷基自由基也可捕获一氧化碳生成酰基 自由基，再与炔基化试剂反应生成炔酮类产物 ${ }^{[25]}$. 激发 态的非金属小分子光催化剂也可以氧化烷基羧酸进而 实现烷基的芳基化与氟化反应 ${ }^{[27,28]}$.
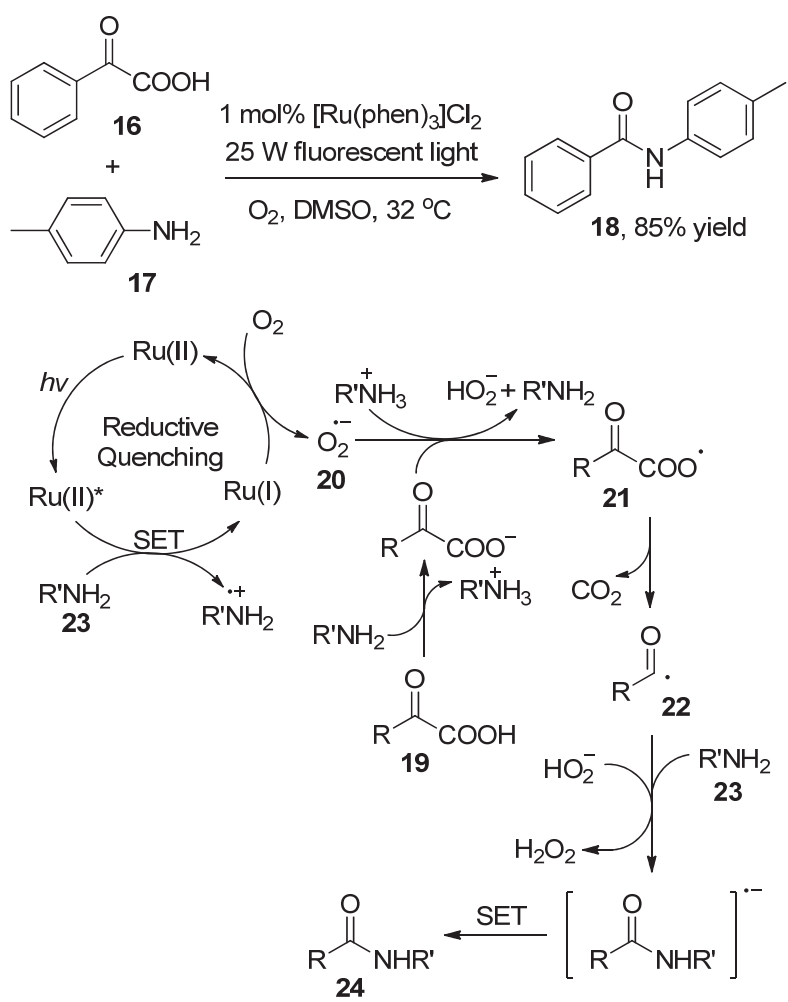

图式 5 反应体系中其它氧化物种直接氧化羧酸产生羧酸自由基 Scheme 5 The carboxyl radical generation from direct carboxylate oxidation with other oxidative species
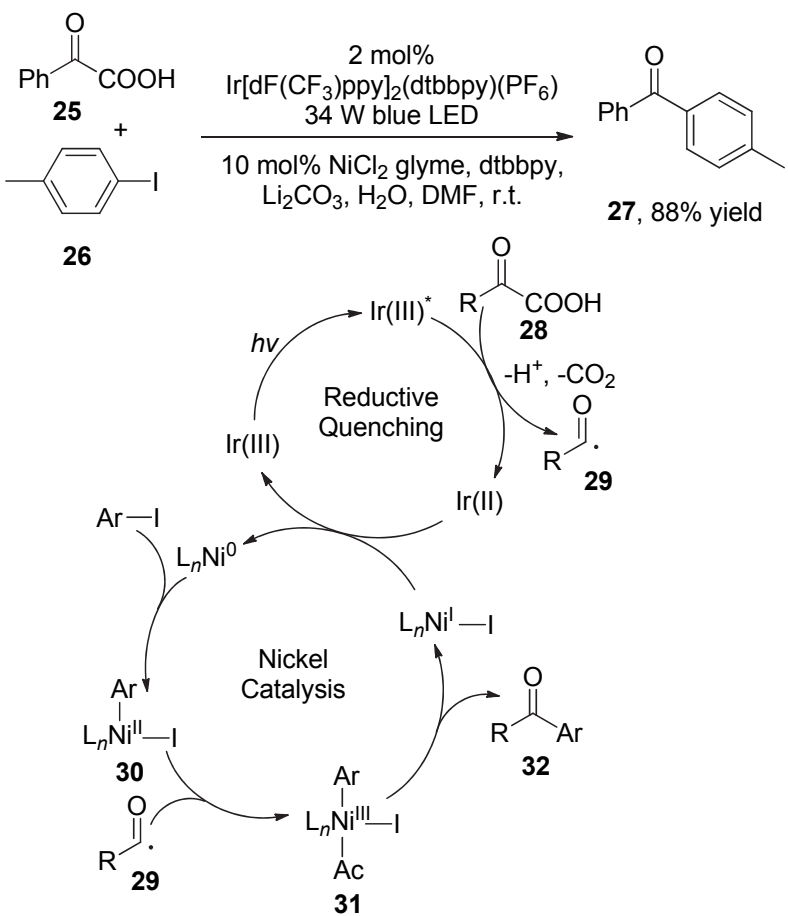

图式 6 激发态光催化剂直接氧化羧酸产生羒酸自由基

Scheme 6 The carboxyl radical generation from direct carboxylate oxidation with excited photocatalyst 
2015 年, 陈以昀课题组 ${ }^{[29]}$ 报道了酮酸 36 在高价碘/ 光催化的双催化体系下, 被环状三价碘试剂 BIOAc 当 场活化形成环状三价碘-酮酸中间体 37 , 进而被氧化态 的光催化剂 $\mathrm{Ru}(\mathrm{III})$ 单电子氧化产生酮酸自由基(Scheme 7). 酩酸自由基脱羧产生酰基自由基 38, 并加成至高价 碘炔基化合物产生炔酮类产物 39. 释放的三价碘 BI 自 由基可以氧化激发态的光催化剂 $\mathrm{Ru}(\mathrm{II})^{*}$ 生成 $\mathrm{Ru}(\mathrm{III})$. 该类光催化/高价碘催化的双催化体系不仅可以在有机 相中顺利进行, 在中性水相体系中也可进行, 并且与氨 基酸、核苷、寡糖、核酸、蛋白及细胞裂解液等生物分

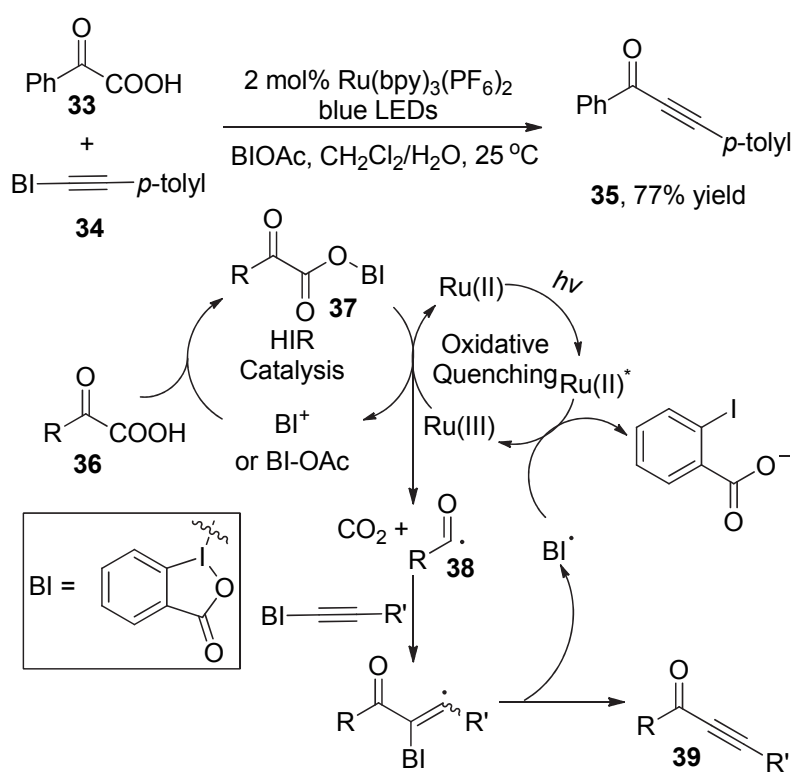

图式 7 氧化态光催化剂氧化被当场活化的羧酸产生羧酸自由基 Scheme 7 The carboxyl radical generation from in situ activated carboxylate oxidation with oxidized photocatalyst
子体系兼容. 2015 年, 王䂞课题组 ${ }^{[30]}$ 发现环状三价碘一 酮酸中间体可以在太阳光照射下直接产生酮酸自由基, 之后脱羧产生酰基自由基，进而发生炔基化反应。

\section{3 可见光引发烷氧自由基的产生及反应}

\section{1 醇衍生物作为自由基前体}

在光催化还原条件下, 还原态的光催化剂可以使醇 的衍生物发生单电子还原产生烷氧自由基. $N$-烷氧邻苯 二甲酰亚胺是非常稳定且易制备的烷氧自由基前体，但 传统产生烷氧自由基的条件导致含化学敏感官能团底 物的不兼容性，进而限制了烷氧自由基的应用. 2016 年, 陈以昀课题组 ${ }^{[31]}$ 报道了 $N$-烷氧邻苯二甲酰亚胺 43 在汉 斯酯作为还原剂的可见光催化还原条件下，被还原态的 光催化剂 $\operatorname{Ir}(\mathrm{II})$ 单电子还原产生 $N$-烷氧邻苯二甲酰亚胺 自由基负离子 44 (Scheme 8). 汉斯酯自由基正离子 45 转移质子使该中间体发生 $\mathrm{N}-\mathrm{O}$ 键的断裂进而产生烷氧 自由基 46. 烷氧自由基 46 发生 1,5-氢迁移反应并被自 由基受体烯丙基砜 41 捕获得到碳氢键的烯丙基化产物 47.

2016 年, Meggers 课题组 ${ }^{[32]}$ 发现 $N$-烷氧邻苯二甲酰 亚胺生成的烷氧自由基在手性催化剂存在下，可以发生 1,5-氢迁移反应串联手性加成反应(Scheme 9). 在该反 应中, $N$-烷氧邻苯二甲酰亚胺在汉斯酯作为还原剂的可 见光催化还原条件下产生烷氧自由基 53 及烷基自由基 54. 该烷基自由基 54 与手性催化剂 $\mathrm{Rh}$ 配位的自由基烯 烃受体 55 发生加成反应得到自由基中间体 56, 然后通 过氢转移得到 $\mathrm{Rh}$ 配合物 $\mathbf{5 7}$, 最终释放手性催化剂得到 加成产物 58.

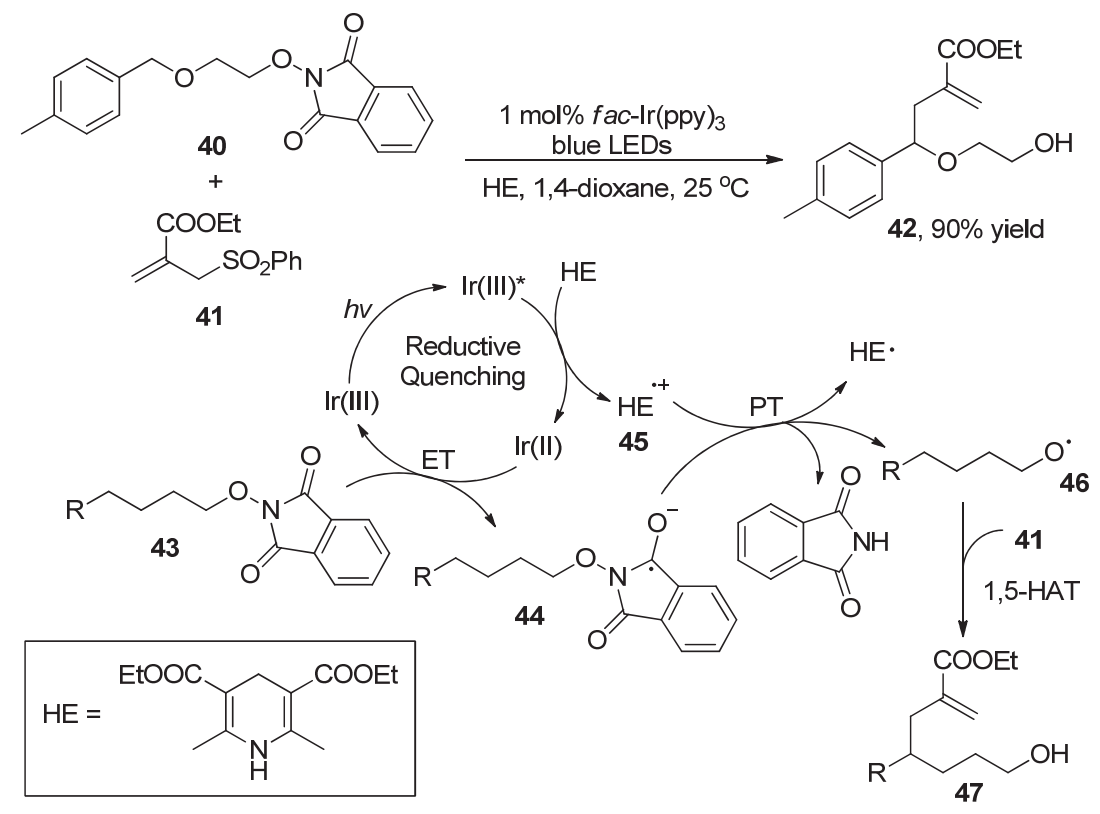

图式 8 还原态光催化剂还原 $N$-烷氧邻苯二甲酰亚胺产生烷氧自由基

Scheme 8 The alkoxyl radical generation from $N$-alkoxyphthalimides reduction with reduced photocatalyst 

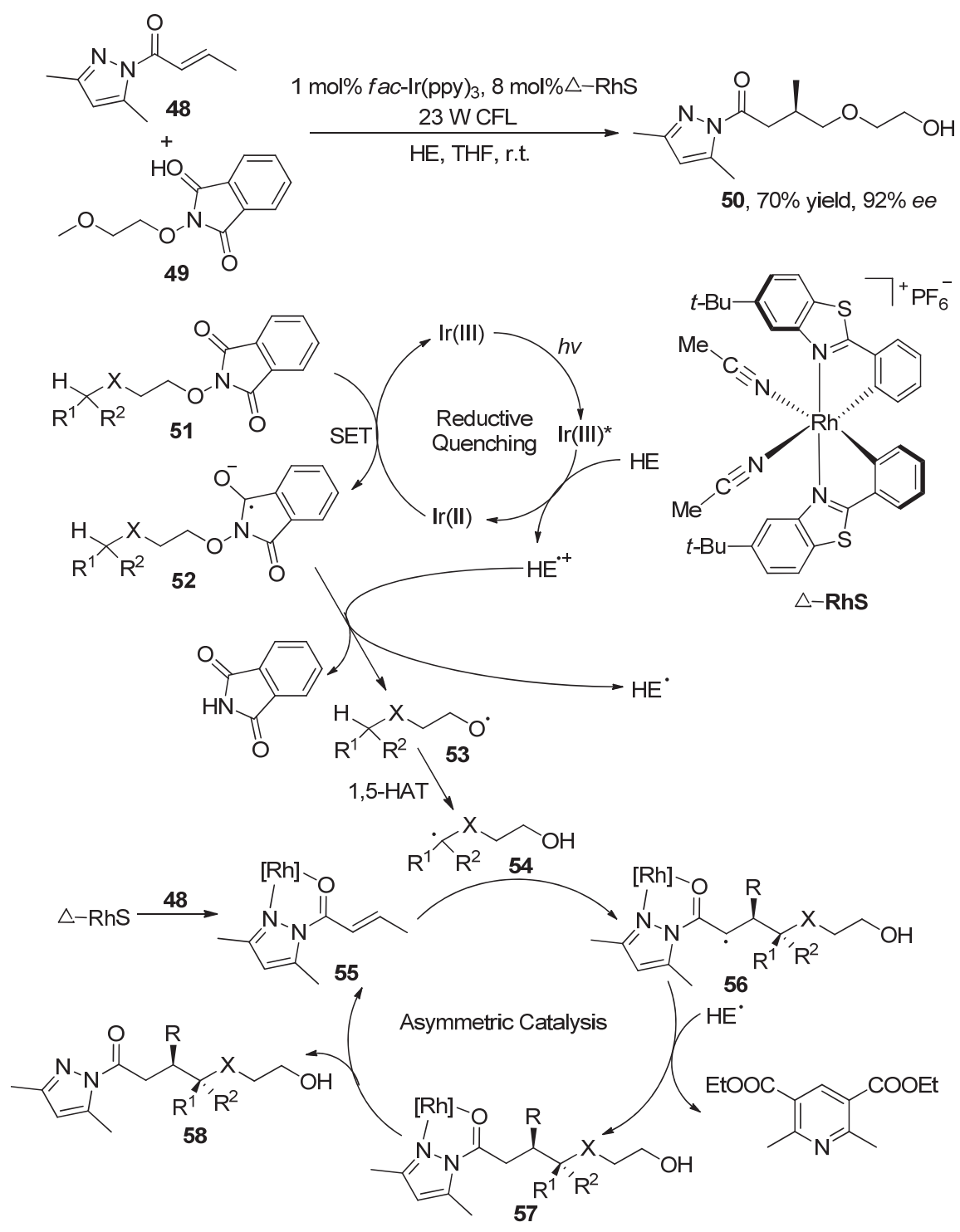

图式 9 还原态光催化剂还原 $N$-烷氧邻苯二甲酰亚胺产生烷氧自由基及不对称催化

Scheme 9 The alkoxyl radical generation from $N$-alkoxyphthalimides reduction with reduced photocatalyst and subsequent asymmetric induction

\section{2 醇作为自由基前体}

醇是理想的烷氧自由基前体, 然而醇均裂的方法生 成烷氧自由基在热力学上需要较高的能量, 在合成上比 较困难, 通常需要在过渡金属活化和较强的氧化条件下 氧化醇产生烷氧自由基. 2016 年, 陈以昀课题组 ${ }^{[33]}$ 报道 了环状醇 59 和线性醇 62 在高价碘/光催化的双催化体系 下, 被环状三价碘 BIOAc 当场活化形成环状三价碘-醇 中间体 63, 进而被氧化态的光催化剂 $\mathrm{Ru}(\mathrm{III})$ 单电子氧 化产生烷氧自由基 64 (Scheme 10). 烷氧自由基发生 $\beta$ 碳碳断裂反应产生烷基自由基 $\mathbf{6 5}$, 进而被炔基化和烯 基化试剂捕获实现炔键及烯键的构建.

2016 年, Knowles 课题组 ${ }^{[34]}$ 报道了可见光条件下质 子偶合的电子转移可以促进烷氧自由基的生成, 进而发
生环状醇的 $\beta$-断裂加氢反应(Scheme 11). 环状醇 67 被 激发态的 $\mathrm{Ir}(\mathrm{III})$ *氧化生成自由基阳离子 69 并生成还原 态 $\operatorname{Ir}(\mathrm{II})$, 进而通过分子内的质子偶合的电子转移过程 生成烷氧自由基 70. 烷氧自由基 70 发生 $\beta$-断裂反应产 生烷基自由基 71, 随即捕获苯硫酚生成开环氢化产物 68.

2016 年, 左智伟课题组 ${ }^{[35]}$ 报道了环状醇 72 被三氯 化铈活化形成醇铈(III)中间体 74, 在可见光照射下生成 激发态醇铈(III)中间体 75 并与自由基 78 发生电子转移 得到醇铈(IV)中间体 76, 具有强氧化性的 Ce(IV)将醇氧 化产生烷氧自由基并进一步发生 $\beta$-断裂反应产生烷基 自由基 77, 最终被捕获得到自由基 78 并释放三氯化铈 (Scheme 12). 


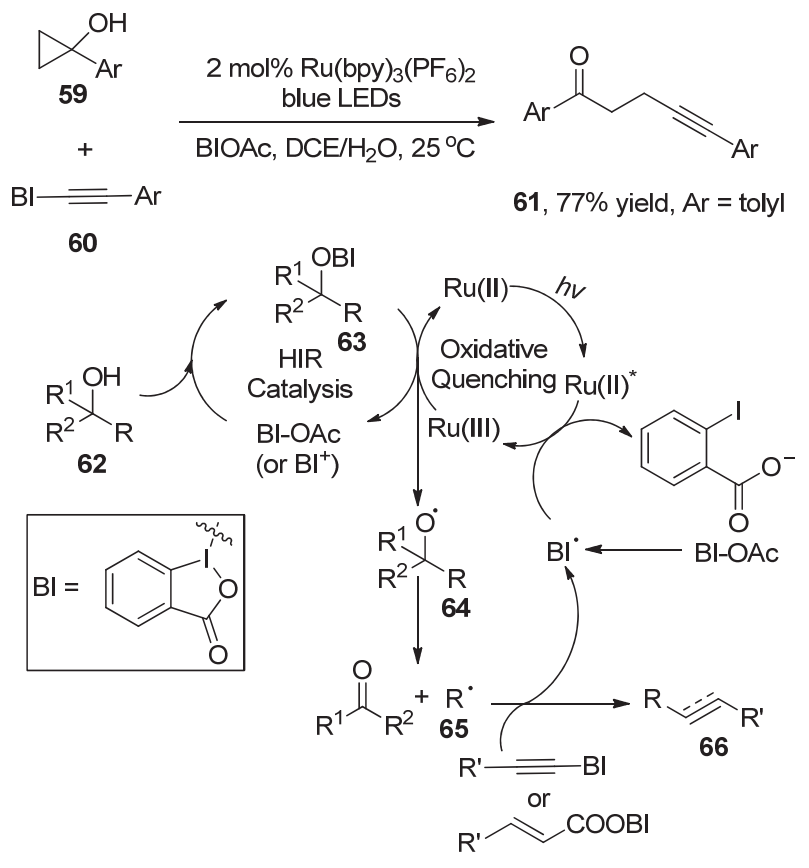

图式 10 氧化态光催化剂氧化被当场活化的醇产生烷氧自由基

Scheme 10 The alkoxyl radical generation from in situ activated alcohol oxidation with oxidized photocatalyst

\section{4 可见光引发其它氧自由基的产生及反应}

2016 年, 肖文精课题组 ${ }^{[36]}$ 报道了肟在有机光催化 条件下氧化产生肟自由基, 进而发生烯烃双官能团化反 应(Scheme 13). 在光氧化条件下, TEMPO 被激发态的 光催化剂鲐啶酯*氧化成 $\mathrm{TEMPO}^{+}$. TEMPO ${ }^{+}$进而氧化肜

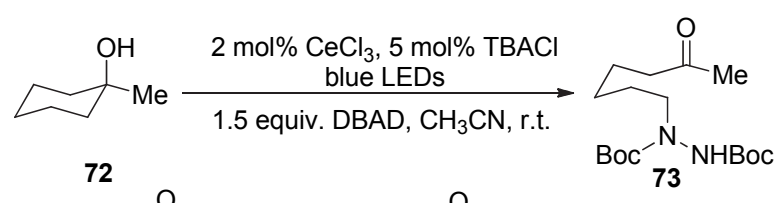

72<smiles>CC(=O)OC(=O)NN(C)CC(C)C(C)C(C)=O</smiles>
$78 \mathrm{Boc}$ Boc 73<smiles>CC1(O[Ge])CCCCC1(C)OC(=O)Cl</smiles>

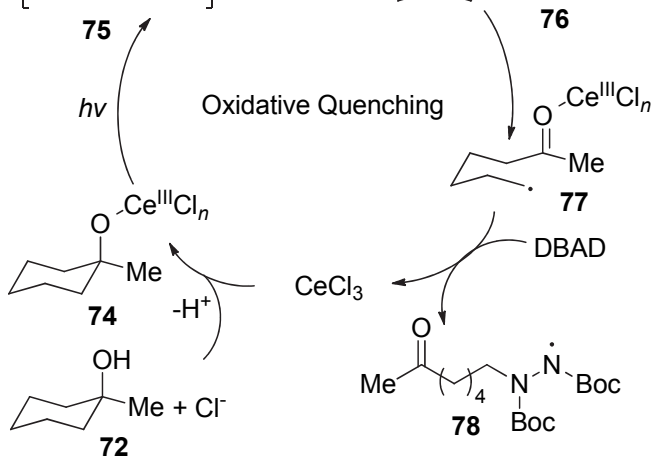

图式 12 氧化态光催化剂 $\mathrm{Ce}(\mathrm{IV})$ 复合物氧化被当场活化的醇产生烷 氧自由基

Scheme 12 The alkoxyl radical generation from in situ activated alcohol oxidation with oxidized photocatalyst Ce(IV) complex

负离子 81 生成肜自由基 82 . 肜自由基 82 发生 5-exo 自 由基环化反应得到烷基自由基 $\mathbf{8 3}$, 被氧气捕获生成烷 基过氧自由基 84, 最后通过质子化与还原得到过氧化 合物 85 及醇 80.
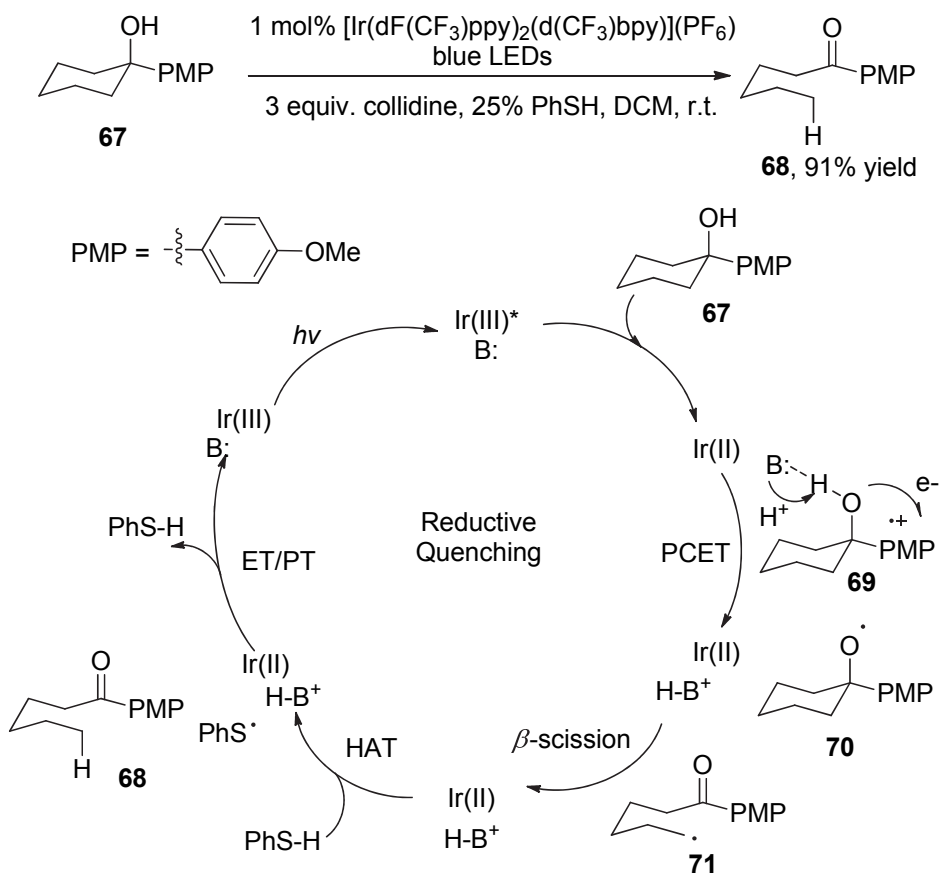

图式 11 激发态光催化剂通过质子偶合的电子转移机理氧化醇产生烷氧自由基

Scheme 11 The alkoxyl radical generation from alcohol oxidation with excited photocatalyst by PCET mechanism 

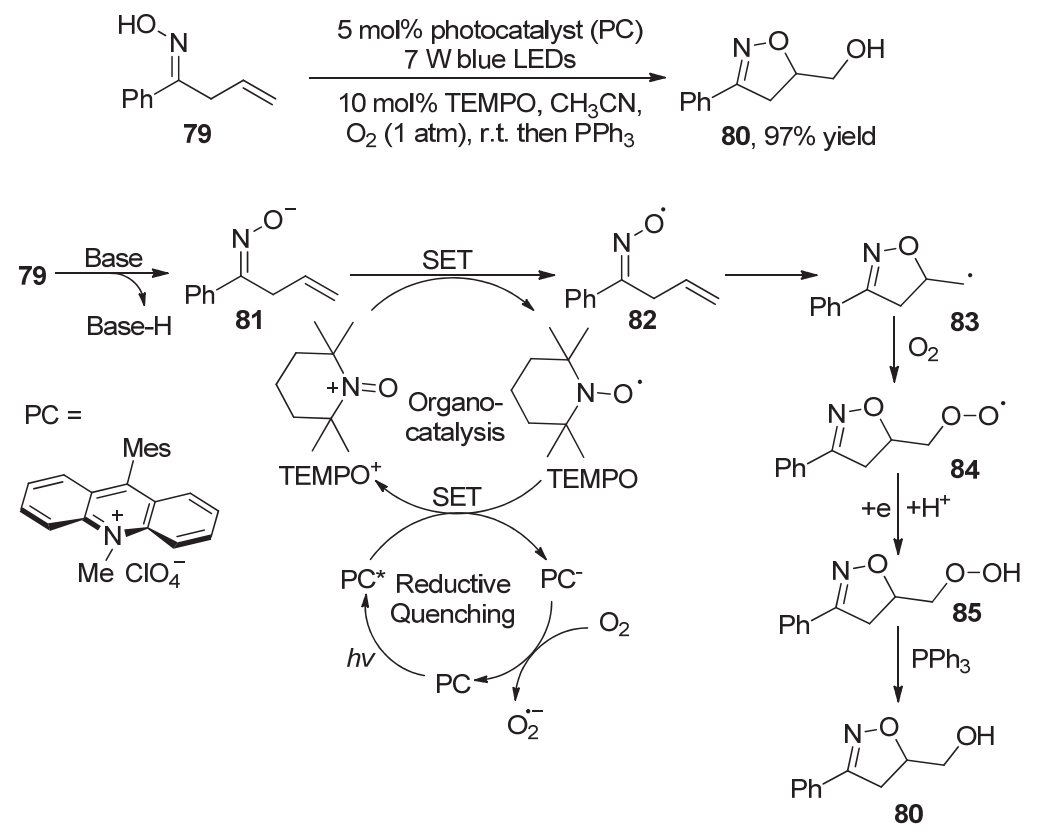

图式 13 反应体系中其它氧化物种直接氧化肜产生肜自由基

Scheme 13 The oxime radical generation from direct oxime oxidation with other oxidative species

\section{5 小结与展望}

介绍了可见光催化氧化还原条件下的氧自由基生 成及反应, 包括烷基羧酸衍生物、酮酸衍生物、醇衍生 物在可见光引发的单电子还原条件下生成羧酸及烷氧 自由基，以及烷基羧酸、酮酸、醇、肜在可见光引发的 单电子氧化条件下生成羧酸、烷氧及肜自由基. 可见光 催化氧化还原条件下氧自由基的新型生成方式具有温 和的反应条件，优秀的化学选择性及官能团普适性，将 在现代有机化学及化学生物学研究中具有良好的应用 前景，同时也将推动其它氧自由基的新型生成方式的发 展与反应研究.

\section{作者简介}

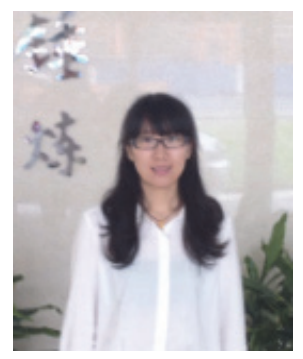

张晶, 1989 年出生于天津, 2012 年于四川大学获得化学学 士学位. 同年进入中国科学院上海有机化学研究所陈以昀课 题组, 目前博士在读. 研究方向为发展可见光引发的新型生 物相容反应。

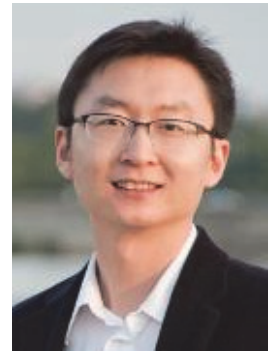

陈以昀, 2002 年在北京大学获得化学学士学位, 2007 年在 普林斯顿大学获得化学博士学位, 2007 2011 年在哈佛大学 和霍华德休斯医学研究所进行化学生物学博士后研究. 2011 年起任上海有机化学研究所 “百人计划” 研究员、课题组长, 2012 年 2 月入选第七批国家“千人计划(青年项目)”，研究兴 趣为发展新的生物相容的光化学方法用于化学生物学的研究.

\section{References}

[1] Gooßen, L. J.; Rodríguez, N.; Gooßen, K. Angew. Chem., Int. Ed. 2008, 47,3100

[2] Xuan, J.; Zhang, Z. G.; Xiao, W. J. Angew. Chem., Int. Ed. 2015, 54, 15632 .

[3] Huang, H.; Jia, K.; Chen, Y. ACS Catal. 2016, 6, 4983.

[4] Guan, B.; Xu, X.; Wang, H.; Li, X. Chin. J. Org. Chem. 2016, 36, 1564 (in Chinese). (关保川, 许孝良，王红，李小年，有机化学, 2016, 36, 1564.)

[5] Čeković, Ž. Tetrahedron 2003, 59, 8073.

[6] Boto, A.; Hernandez, D.; Hernandez, R.; Suárez, E. J. Org. Chem. $\mathbf{2 0 0 3}, 68,5310$.

[7] Salamone, M.; Bietti, M. Acc. Chem. Res. 2015, 48, 2895.

[8] Prier, C. K.; Rankic, D. A.; MacMillan, D. W. C. Chem. Rev. 2013, 113,5322 .

[9] Schultz, D. M.; Yoon, T. P. Science2014, 343, 985.

[10] Narayanam, J. M. R.; Stephenson, C. R. J. Chem. Soc. Rev. 2011, 40, 102.

[11] Xuan, J.; Xiao, W. J. Angew. Chem., Int. Ed. 2012, 51, 6828

[12] Hu, C. C.; Chen, Y. Y. Tetrahedron Lett. 2015, 56, 884. 
[13] Okada, K.; Okamoto, K.; Morita, N.; Okubo, K.; Oda, M. J. Am. Chem. Soc. 1991, 113, 9401.

[14] Schnermann, M. J.; Overman, L. E. Angew. Chem., Int. Ed. 2012, $51,9576$.

[15] Yang, J.; Zhang, J.; Qi, L.; Hu, C. C.; Chen, Y. Y. Chem. Commun. 2015, 51, 5275 .

[16] Hu, C. C.; Chen, Y. Y. Org. Chem. Front. 2015, 2, 1352.

[17] Xie, J.; Xu, P.; Li, H. M.; Xue, Q. C.; Jin, H. M.; Cheng, Y. X.; Zhu, C. J. Chem. Commun. 2013, 49, 5672.

[18] He, Z.; Bae, M.; Wu, J.; Jamison, T. F. Angew. Chem., Int. Ed. 2014, 53,14451 .

[19] Kachkovskyi, G.; Faderl, C.; Reiser, O. Adv. Synth. Catal. 2013, 355,2240

[20] Zuo, Z. W.; MacMillan, D. W. C. J. Am. Chem. Soc. 2014, 136, 5257.

[21] Ventre, S.; Petronijevic, F. R.; MacMillan, D. W. C. J. Am. Chem. Soc. 2015, 137, 5654.

[22] Liu, J.; Liu, Q.; Yi, H.; Qin, C.; Bai, R. P.; Qi, X. T.; Lan, Y.; Lei, A. W. Angew. Chem., Int. Ed. 2014, 53, 502.

[23] Chu, L. L.; Lipshultz, J. M.; MacMillan, D. W. C. Angew. Chem., Int. Ed. 2015, 54, 7929.

[24] Wang, G. Z.; Shang, R.; Cheng, W. M.; Fu, Y. Org. Lett. 2015, 17, 4830 .
[25] Zhou, Q. Q.; Guo, W.; Ding, W.; Wu, X.; Chen, X.; Lu, L. Q.; Xiao, W. J. Angew. Chem., Int. Ed. 2015, 54, 11196.

[26] Le Vaillant, F.; Courant, T.; Waser, J. Angew. Chem., Int. Ed. 2015 54, 11200.

[27] Wu, X. X.; Meng, C. N.; Yuan, X. Q.; Jia, X. T.; Qian, X. H.; Ye, J. X. Chem. Commun. 2015, 51, 11864.

[28] Luo, J.; Zhang, J. ACS Catal.2016, 6, 873.

[29] Huang, H. C.; Zhang, G. J.; Chen, Y. Y. Angew. Chem., Int. Ed. 2015, 54, 7872 .

[30] Tan, H.; Li, H. J.; Ji, W. Q.; Wang, L. Angew. Chem. Int. Ed. 2015, 54,8374 .

[31] Zhang, J.; Li, Y.; Zhang, F. Y.; Hu, C. C.; Chen, Y. Y. Angew Chem., Int. Ed. 2016, 55, 1872.

[32] Wang, C. Y.; Harms, K.; Meggers, E. Angew. Chem., Int. Ed. 2016 , $55,13495$.

[33] Jia, K. F.; Zhang, F. Y.; Huang, H. C.; Chen, Y. Y. J. Am. Chem. Soc. 2016, 138, 1514.

[34] Yayla, H. G.; Wang, H. J.; Tarantino, K. T.; Orbe, H. S.; Knowles, R. R. J. Am. Chem. Soc. 2016, 138, 10794.

[35] Guo, J. J.; Hu, A. H.; Chen, Y. L.; Sun, J. F.; Tang, H. M.; Zuo, Z. W. Angew. Chem., Int. Ed. 2016, 55, 15319.

[36] Hu, X. Q.; Chen, J.; Chen, J. R.; Yan, D. M.; Xiao, W. J. Chem. Eur. J. 2016, 22, 14141 . 